\title{
NEIBA
}

\section{A onda neoliberal e os seus efeitos assimétricos no desempenho econômico da América Latina e da Ásia Oriental}

\author{
Bruna Machado Targino ${ }^{1}$ e Eduardo Alberto Crespo 2
}

Vínculo Institucional: ${ }^{1}$ Mestranda em História no Centro de Pesquisa e Documentação de História Contemporânea na Fundação Getúlio Vargas (CPDOC/FGV). Graduada em Defesa e Gestão Estratégica Internacional pela Universidade Federal do Rio de Janeiro (DGEI/UFRJ). Contato: bruna.targino@coppead.ufrj.br

2 Prof. Dr. no Programa de Pós-Graduação em Economia Política Internacional na Universidade Federal do Rio de Janeiro (PEPI/UFRJ). Contato: ecres7o@gmail.com.br

\section{Resumo:}

A partir do século XIX, o mundo experimentou as primeiras consequências globais da Revolução Industrial e a incontestável hegemonia econômica e geopolítica do "Ocidente". Nesse período, a América Latina apresentou desempenhos mais favoráveis do que a Ásia Oriental tanto em termos econômicos quanto na sua capacidade de consolidar Estados modernos e centralizados. Contudo, essa realidade começou a mudar nos primeiros anos do pós-guerra com a descolonização e a formação de Estados centralizados na Ásia. Depois, com notável intensidade, a América Latina sofreu as consequências das crises financeiras da década de 1970 e a implementação de políticas neoliberais, que desmontaram os mecanismos estatais de promoção ao desenvolvimento - orientação que não atingiu a Ásia Oriental no mesmo grau. Nesse sentido, para discutir o desempenho econômico de ambas regiões em longo prazo, oferecemos algumas chaves para interpretar a "inversão de fortunas"com base nos impactos da guerra, na concorrência interestatal e na coesão social.

Palavras-chaves:

América Latina; Ásia Oriental; Neoliberalismo. 


\title{
NEIBA
}

\section{8}

\begin{abstract}
:
During the 19th century, the Industrial Revolution and the Western hegemony produced global consequences to the "rest" of the world. While Latin America performed better results in terms of economic development and State centralization, East Asia suffered the European imperialism interventions on their territory. Then, both performances were reversed with the decolonization of Asian countries and Latin America, intensively, suffered the consequences of the financial crisis of the 1970 s and the implementation of neoliberal policies, which dismantled State's development mechanisms. This process did not affect East Asia in the same way. In view of this, the present article makes a comparative study between the economic performance of both regions from the "Great Divergence". Thus, we offer some keys to interpret the "inversion of fortunes" based on the impacts of war, interstate competition, and social cohesion.
\end{abstract}

Keywords:

Latin America; East Asia; neoliberal global order. 


\section{NEİBA}

\section{Introdução}

A partir do século XIX, a economia mundial experimentou dois processos complementares. O primeiro trata-se de uma tendência mundial ao crescimento econômico, ainda que afetado por crises e flutuações cíclicas. Nesse momento, o desenvolvimento econômico tornou-se uma meta a ser alcançada e uma condição fundamental para estruturar as relações de poder global. O segundo refere-se ao crescimento desigual entre as regiões e os agrupamentos de países, movimento denominado por alguns autores como a "Grande Divergência". Esse fenômeno dividiu o mundo entre países ricos e pobres; centrais e periféricos (POMERANZ, 2000). A grande divergência entre as taxas de crescimento da Europa Ocidental e as antigas colônias britânicas em relação ao "restante" do planeta ocorreu aproximadamente entre 1820 e 1950: período marcado pelas grandes transformações técnico-materiais conhecidas como Primeira e Segunda Revolução Industrial.

Nesse período, o processo de industrialização e de desenvolvimento capitalista gerou condições econômicas e geopolíticas diferentes, de acordo com a região. Na periferia do sistema internacional, o subdesenvolvimento atingiu a maior parte do continente asiático, a África Subsaariana, o norte da África e o Oriente Médio, a América Latina e o Caribe. O Japão, principal exceção ao "Milagre Europeu", foi o único país com uma população não europeia que, no final do século XIX, conseguiu unificar-se, organizar um Estado Moderno e iniciar um processo acelerado de industrialização (JONES, 1981). Essas regiões tiveram desempenhos muito diferentes ao longo do tempo. Décadas após a Segunda Guerra Mundial, os países do Leste Asiático se tornaram exemplos bem-sucedidos de desenvolvimento enquanto a América Latina, que desfrutou de padrões de vida e de indicadores sociais muito superiores ao resto da periferia, destacou-se pela sua relativa estagnação econômica. Em termos de renda per capita até 1950, a América Latina era uma "classe média do mundo", superando em muito os níveis de desenvolvimento material na Ásia e na África (NAYYAR,
2013). Diante dessa "inversão de fortunas", este trabalho oferece algumas interpretações sobre por que as políticas neoliberais afetaram o desempenho da América Latina e desmontaram seus mecanismos estatais de promoção ao desenvolvimento enquanto essa orientação não se consolidou da mesma maneira na Ásia Oriental. Para tanto, realizamos um estudo comparativo através de pesquisa bibliográfica com o uso de dados secundários que visa contrapor o desempenho econômico em ambas as regiões a partir de análises orientadas pela coesão social, por questões geopolíticas e pelos impactos da guerra.

A Grande Divergência na periferia: do século XIX aos anos 1980

Durante o século XIX, a América Latina ocupou uma posição relativamente privilegiada na divisão internacional do trabalho enquanto principal região exportadora de matérias-primas e alimentos para Europa - o que resultou em altas taxas de crescimento econômico (FINDLAY \& O'ROURKE, 2009). Nesse momento, a Revolução Industrial trouxe tecnologias que transformaram radicalmente o comércio internacional: as ferrovias e os navios a vapor provocaram uma revolução nos transportes; o telégrafo e depois o telefone fizeram o mesmo com as comunicações. Considerando essas bases tecnológicas, o comércio mundial experimentou um salto sem precedentes. Essas transformações modificariam definitivamente o funcionamento dos territórios que antes compreendiam os impérios espanhol e português. O impacto simultâneo das invasões napoleônicas assim como da hegemonia naval, comercial e financeira da Inglaterra formaram os gatilhos necessários para os processos de independência (NOVAIS, 1989; LYNCH, 1976). A expansão do comércio internacional especialmente a partir da segunda metade do século XIX foi o objetivo e a razão principal de financiamento para criar novos países na região (SAYLOR 2014). Diante de uma conjuntura eurocêntrica, os Estados latino-americanos, abundantes em recursos naturais e dotados de baixa densidade populacional, surgiram como mecanismo 


\section{NEIBA}

facilitador para a venda de mercadorias destinadas ao mercado europeu. A combinação entre características favoráveis para diferentes tipos de agriculturas semelhantes ao modelo europeu,como no Uruguai e no sul do Brasil; técnicas agrícolas e imigração europeia foram a fórmula mágica para decolagem desses espaços desabitados e disponíveis. Quando essas condições se somaram às ferrovias e aos investimentos britânicos em mineração, em companhias de abastecimento de água e de gás, de navegação e em bancos, o salto de produtividade foi incomparável.

Por outro lado, as condições asiáticas durante o século XIX foram adversas. Enquanto a América Latina consolidava Estados, ainda que apenas formalmente independentes, a maioria dos antigos reinos e impérios da Ásia foram transformados em colônias europeias ou japonesas. A China, centro econômico da Ásia Oriental por milênios, aos poucos perdeu graus de liberdade para se tornar um grande espaço de ação imperialista das potências europeias, dos Estados Unidos e do próprio Japão. Ainda menos auspiciosa foi a inserção econômica dos asiáticos na recém-criada divisão internacional do trabalho. Até então, eles haviam sido caracterizados como impérios agrícolas, equipados com grandes mercados e dotados de economias altamente diversificadas para os parâmetros da era préindustrial. As economias asiáticas possuíam capacidades de produção notáveis, conhecidas como "protoindustrialização", que não tinha nada a invejar suas contrapartes na Europa Ocidental, representando aproximadamente $2 / 3$ da produção mundial (BAIROCH, 1982). No entanto, o rápido crescimento europeu devido à revolução industrial e às ações imperialistas que se seguiram também em escalas industriais, desencadeou ao longo do século XIX um processo abrupto de primarização na maioria das sociedades asiáticas, com exceção novamente do Japão. Foi assim que regiões superpovoadas como a Índia e a China tornaram-se exportadores líquidos de produtos primários e importadores de bens manufaturados, quando qualquer avaliação teria sugerido um fluxo comercial na direção inversa. Durante o século XIX, a maioria das populações asiáticas entraram em colapso. Além disso, sofreram com a colonização ou semi-colonização por parte das potências dominantes com a primarização dos processos produtivos em um movimento de "des-urbanização" e "re-ruralização" (GONÇALO, 2018).

Essa situação perdurou até o final da Segunda Guerra Mundial. A Independência da Índia em 1947 e especialmente a revolução comunista na China em 1949 incendiaram a chama emancipatória em toda a região. O exército nacionalista chinês, derrotado no continente, refugiou-se em Taiwan sob proteção dos EUA. Um ano depois, em 1950, eclodiu a Guerra da Coreia, dividindo o país em duas áreas de influência. Em 1954, um exército vietnamita derrotou os franceses, desencadeando a gradual e crescente intervenção dos EUA até sua retirada e derrota em 1975. A comoção se espalhou pela região. Em alguns países, isso desencadeou repressões brutais com consequências econômicas regressivas, como a Indonésia em 1965; ou reformas bem-sucedidas como na Malásia. O Leste asiático viveu o período pós-guerra como a área quente da Guerra Fria. Os novos estados nasceram lá para fazer guerras, como havia acontecido na Europa séculos antes.

Para conter a onda revolucionária chinesa, o governo dos Estados Unidos elaborou a política do "cordão sanitário" de contenção militar e econômica em toda a sua região circundante. Assim, atingiu grande parte da área geográfica que durante séculos compôs o antigo sistema tributário na Ásia Oriental (HAMASHITA, 2008). Foi nessa periferia da China que se registraram os casos mais ressonantes de desenvolvimento econômico tardio: Coréia do Sul, Taiwan, Hong Kong ${ }^{3}$ e Singapura ${ }^{4}$. Considerando o
3 Cidade originária da China controlada pelos britânicos desde o Tratado de Nanking (1842), que deu fim à Primeira Guerra do Ópio e que atuou como "dobradiça" financeira e comercial entre o Ocidente e a China continental.

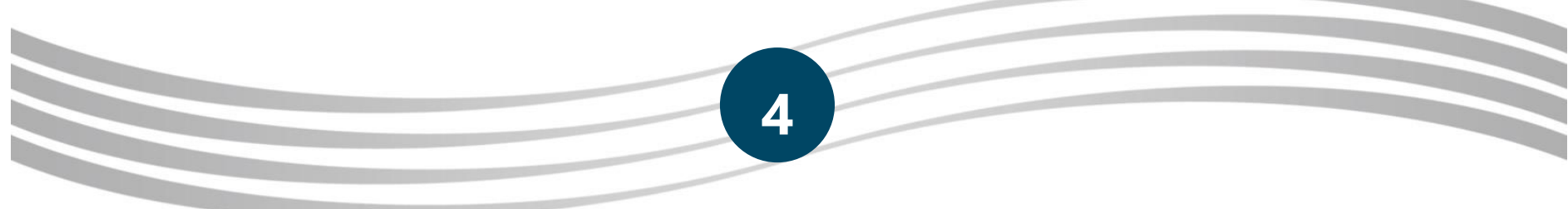




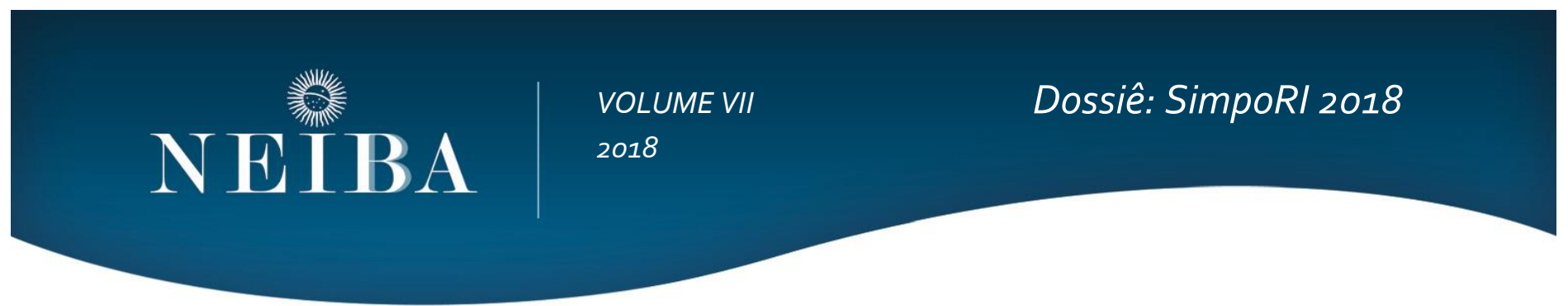

exemplo japonês, a guerra (social e internacional) ou sua ameaça iminente e o apoio norte-americano contribuíram para formar sociedades coesas; Estados poderosos e capazes de incentivar a acumulação de capital. Para tanto, orientaram-se por objetivos pré-determinados em matéria de produtividade, adoção e desenvolvimento de tecnologias, metas de exportação, etc. Durante a década de 1970, quando as relações entre a China e os Estados Unidos se afrouxaram, o desenvolvimento da periferia da China começou a se reconectar com o continente e o "Império do Meio", núcleo milenar do antigo sistema tributário. Isso ocorreu por meio do aumento do fluxo de investimentos internacionais, da abertura de mercados externos e da utilização de seu enorme e crescente mercado (ARRIGHI, 2009).Desde então, a China tem experimentado o mais impressionante processo de desenvolvimento conhecido na história. Em 40 anos, a produção per capita cresceu a taxas extraordinárias; centenas de milhões de chineses abandonaram a pobreza e o país está se tornando a maior economia do mundo.

Na América Latina, a Primeira Guerra Mundial e especialmente a crise de 1929 afetaram as exportações. O virtual colapso do comércio internacional inevitavelmente provocou mudanças radicais em um continente organizado para a exportação. Em 1930, ocorreram rupturas políticas e também se formaram novas coligações governamentais em quase todos os países latino-americanos. Os novos regimes, maioria de orientação populista, por exemplo, Getúlio Vargas no Brasil e Juan Perón na Argentina, procuraram reorientar suas economias em direções alternativas. Como a acumulação de capital com base nos mercados externos foi praticamente cancelada pela crise, concentraram esforços em promover processos de acumulação destinados aos mercados domésticos. A criação de empresas públicas em setores estratégicos e o aumento nos gastos do governo para compensar a menor demanda privada caracterizam esse

\footnotetext{
4 Por sua localização estratégica, Singapura é uma "dobradiça" comercial entre os Oceanos Indico e Pacífico. Por isso, sempre foi objeto de disputa pelos colonizadores europeus.
}

período. Durante a Segunda Guerra Mundial, coincidindo com o que aconteceu em todo o Ocidente, houve uma distribuição de renda mais igualitária. A partir de então, a expansão do mercado interno e o apoio político dos trabalhadores urbanos tornaram-se partes essenciais das novas coalizões em que os militares, os sindicatos e a classe média urbana convergiam com os empresários que foram favorecidos pelo crescimento da demanda doméstica.

O desempenho econômico da América Latina tem sido desigual desde então. Os países mais populosos e os mercados internos com maior potencial tiveram melhor desempenho. Os processos de industrialização atingiram níveis de complexidade intermediária apenas no Brasil, no México e, em menor grau, na Argentina. A estreiteza do mercado tornou breves as experiências industriais das pequenas economias. Embora tenham experimentado os estágios iniciais do processo, invariavelmente acabaram retomando suas diretrizes tradicionais de livre comércio em meados da década de 1980 . A restrição externa das moedas foi, durante esse estágio, a limitação econômica mais conhecida e estudada pelos países latino-americanos. Os conflitos distributivos e os ciclos de natureza política que estavam associados à restrição externa tornaram o desenvolvimento do subcontinente mais dramático. Mesmo diante da crise financeira do final da década de 1970, os regimes de substituição de importações reduziram os efeitos da conjuntura internacional e da deterioração dos termos de troca. Assim, apesar do contexto desfavorável, a América Latina estava vários passos à frente da Ásia em termos de desenvolvimento econômico ; de competição tecnológica e de condições de vida. O que aconteceu desde então? Por que o desempenho da América Latina foi tão decepcionante em comparação com o da Ásia?

\section{Guerra e Estado}

A competição entre grupos e a guerra nas suas diferentes nuances, historicamente, atuaram como fator fundamental para qualquer organização humana. Em 


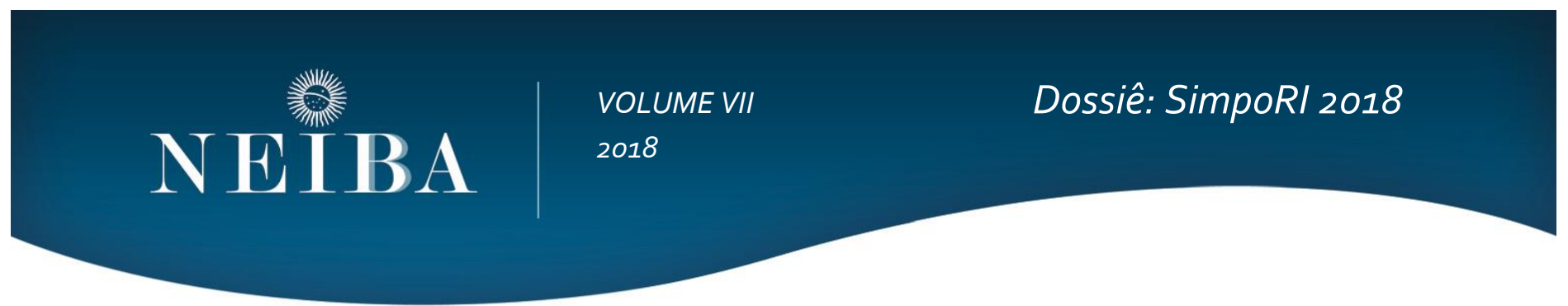

particular, o tipo de guerra ou ameaça de guerra predominante ajuda a definir o modo como todos os grupos humanos funcionam. A identificação dos inimigos é uma característica distintiva das forças armadas do Leste Asiático em comparação com suas contrapartes latino-americanas. Enquanto para a primeira região as ameaças estão localizadas principalmente fora do território sob jurisdição de seus Estados, isto é, concentram-se em inimigos "externos", para a América Latina, encontram-se invariavelmente dentro do território nacional vestidos com roupas diversas como "comunistas", partidos de orientação popular, sindicalistas, estudantes.

O funcionamento das organizações estatais se difere de acordo com os inimigos que possui, se são outros Estados ou organizações não estatais. Por exemplo, uma característica distintiva da trajetória histórica dos países europeus em relação aos asiáticos foi seu longo processo seletivo mediado pelas guerras interestatais. O Império Chinês, por outro lado, teve apenas que enfrentar a ameaça persistente das tribos nômades da Ásia Central que não possuíam Estados. O tipo de guerra, consequentemente, era invariavelmente diferente. As armas que foram eficazes em conflitos europeus não funcionaram em conflitos chineses. A relação intrínseca entre a capacidade de tributar, gastar e promover o desenvolvimento técnico-militar estava ausente na China, mas era estrutural na Europa.

No entanto, após os efeitos da penetração europeia da Ásia nos séculos XIX e XX, somente os Estados autônomos organizados sob moldes análogos aos europeus poderiam reaparecer. Isto é,Estados coesos, centralizados, dotados de alta capacidade tributária e de condições materiais para travar guerras visto que as assimetrias técnico-materiais em relação aos europeus contribuíram para intensificar a instabilidade interna, como aconteceu na China.Nesse sentido, a geopolítica asiática da segunda metade do século $X X$ impediu o ressurgimento de organizações estatais no estilo dos antigos impérios. Após a "breve" colonização ou semi-colonização por estrangeiros, as novas elites asiáticas priorizaram a consolidação de suas autonomias nacionais e a modernização para libertar-se da pressão imperialista europeia e japonesa. Além disso, para enfrentar o confronto global entre os Estados Unidos e a União Soviética. O desenvolvimento econômico e a inclusão de seus habitantes na comunidade imaginária nacional eram tarefas essenciais para a estabilidade política e para a sobrevivência do Estado.

Nada semelhante aconteceu na América Latina. Tanto no século XIX quanto no $X X$, as elites que governaram os Estados latino-americanos exerceram soberania sobre grandes territórios sem a necessidade de recorrer a grandes guerras, mobilizações de massa ou iniciativas industriais desesperadas. O desenvolvimento econômico na América Latina não era um imperativo para a subsistência dos Estados nem para a preservação das hierarquias políticas. Essas políticas eram defendidas, em todo caso, por conta de seus possíveis efeitos sobre a qualidade de vida e com base em critérios de equidade social. Não representavam, portanto, uma condição de vida ou morte, especialmente para as elites governantes.

\section{Onda neoliberal e restrições geopolíticas}

Após a Segunda Guerra, a economia mundial abriuse outra vez. No entanto, a segunda onda de globalização liderada pelos EUA estabeleceu relações econômicas mundiais altamente reguladas até o final da década de 1970. Até esse período, o controle do fluxo de capitais e os regimes de acumulação seguiam as recomendações domésticas. Só a partir do choque das taxas de juros propiciado pela autoridade monetária norte-americana em 1979, a ordem econômica e financeira internacional seria transformada de maneira irreversível. Através de diferentes mecanismos de persuasão e extorsão, o poder norte-americano promoveu a liberalização internacional de capitais; a abertura de mercados e a liberalização comercial e financeira. O estágio avançado do neoliberalismo procurou privar Estados periféricos de seus mecanismos de intervenção, tais como 


\section{NEIBA}

planos explícitos de industrialização, bancos estatais, empresas públicas, regulamentos, políticas comerciais, segmentos produtivos de alto valor agregado.

A experiência do desenvolvimento econômico da América Latina desde então enfrentou o desmantelamento gradual de seus mecanismos de promoção e proteção, que prevaleciam desde a década de 1930. A partir da década de 1980, a inserção externa latino-americana perpassa pela abertura financeira e unilateral para os Estados Unidos; pelo contexto de crise da dívida externa e pelas pressões internacionais por liberalização diante do papel "sufocante" do Estado nos investimentos e nos gastos públicos (PORTELLA FILHO, 1994). Nesse período, diante do esgotamento das políticas do "liberalismo incrustado" que marcaram o pós-Segunda Guerra, os países que viviam o capitalismo avançado apresentaram o neoliberalismo como única saída possível diante da crise através de medidas orientadas pela ortodoxia neoliberal, como por exemplo, as "sugeridas" pelo Consenso de Washington para a América Latina. Essas políticas consistiam na adoção das "leis demercado" como a reavaliação das prioridades nos gastos públicos; a privatização de empresas estatais; a desregulamentação de atividades econômicas e a garantia dos direitos de propriedade (BANDEIRA, 2002).

Na Ásia, o fim da Guerra Fria e as demandas por democratização também facilitaram o surgimento de coalizões neoliberais desejosas por desarmar os mecanismos de intervenção estatal; liberalizar o comércio; abrir o mercado de capitais. Mas, a persistente pressão geopolítica sobre a Ásia permitiu diferenciar esta região da América Latina. A pressão militar e a persistência de ameaças genuínas ao Estado questionam qualquer reviravolta neoliberal diante de um cenário que comprometa a continuidade do crescimento; a unidade do Estado ou a estabilidade das hierarquias políticas. Embora as burocracias estatais e militares que comandaram os países da região após a Guerra Fria tenham acumulado poder ao longo do tempo, as burguesias nacionais ainda possuem habilidade política suficiente para definir a orientação geral de suas economias.

Ao se inserir no capitalismo global na forma de "socialismo de mercado com características chinesas", a China se diferencia dos demais países asiáticos. Desde o início das reformas em 1978, a ascensão chinesa teve como pilar fundamental as iniciativas do Partido-Estado, que planeja e conduz a contínua e rápida reconstrução de sua base produtiva. Ao contrário das receitas neoliberais dominantes na América Latina, associadas ao desarmamento dos principais instrumentos de intervenção estatal, mas ainda em linha com os moldes de um Estado capitalista, o Partido-Estado chinês tem preservado todos os principais instrumentos de desenvolvimento capitalista. Direta ou indiretamente, mantém o controle de preços básicos como taxas de juros, câmbio e salários, regulando os fluxos internacionais de capitais e o sistema financeiro (NOGUEIRA, 2018, p.4). Outro fato marcante é a complexidade de sua estrutura de capital. Existem empresas públicas controladas pelo governo central, por governos estaduais, inúmeras empresas mistas, várias formas de parceria público-privada, joint ventures com empresas multinacionais, cooperativas, etc. Esse processo implica na proliferação contínua de novos membros da 'burguesia nacional', que invariavelmente mantêm vínculos com o Partido Comunista Chinês (PCC), que lidera o Estado (LYRIO, 2010).

Por que a China permaneceu alheia à liberalização econômica que prevalecia em outras latitudes? O surgimento do setor privado forte a partir das reformas realizadas por Deng Xiaopingem meados na década de 1980, período de propagação das políticas neoliberais, não desestabilizou a ordem política do país. Ao contrário do que acontece na América Latina, os capitalistas chineses, em vez de pressionarem por reformas neoliberais, tendem a se associar às estratégias de desenvolvimento definidas pelo PCC. Isso não significa que a relação entre a burguesia nacional e o Estado-Partido sejam harmônicas, mas que tendem a 


\section{NEIBA}

convergir de acordo com as conveniências em prol do desenvolvimento econômico cuja pressão ocorre por uma "via de mão dupla". Além de incentivos para se aliar ou oporse às diretrizes estatais, McNally e Wraight (2010) apontam relações afetivas e graus de parentesco entre os principais membros da burguesia nacional e as lideranças "comunistas". Ou seja, há um sentimento generalizado de pertencimento mútuo, afeto e até mesmo de troca de "favores" entre a elite chinesa a partir de critérios estabelecidos pelas assim chamadas práticas de guanxi, derivadas da tradição confucionista, que sofreram mudanças significativas desde o rompimento com o socialismo. A integração dos capitalistas chineses ao Partido, os "capitalistas vermelhos", envolve uma dinâmica política complexa através da qual conciliam as demandas corporativas por lucros com o objetivo político fundamental focado no desenvolvimento econômico e na segurança nacional. Muitos membros da nova burguesia nacional realizam ou ocuparam cargos em instituições públicas no passado. Essa coincidência de interesses dá ao sistema político chinês coesão suficiente para que as intervenções políticas dos capitais privados não bloqueiem as intervenções de desenvolvimento do partido (MCNALLY \& WRIGHT, 2010; DICKSON, 2003).

Apesar desse movimento na China de forte participação estatal, como ficou evidente durante a crise financeira de 1997-1998, os países asiáticos passaram por etapas neoliberais. As economias da região foram atingidas em diferentes graus, dependendo de seus níveis variáveis de liberalização de suas contas de capital e da maior ou menor adoção de políticas "mercantilistas", que consistem no acúmulo de reservas internacionais. No entanto, nos países asiáticos, como faltam recursos naturais enquanto fontes de moeda forte, desde o início, promoveram a industrialização orientada para a exportação e para competição por mercados estrangeiros. Já a industrialização da América Latina, por outro lado, nasceu e se desenvolveu sob o abrigo de mercados domésticos; as moedas vieram de exportações tradicionais baseadas em recursos naturais. Era compreensível que os asiáticos tivessem um desempenho industrial mais auspicioso em economias mais abertas.

Isto é, durante séculos, o desempenho dos Estados da Ásia como Japão, Coreia e Vietnã se basearam em organizações burocráticas competentes. Os funcionários públicos, por exemplo, foram escolhidos por meio de critérios meritocráticos - ainda que bastante questionáveis. Desde o século VII, durante a dinastia Tang, o acesso ao mandarinato na China baseava-se na aprovação de competições públicas que consistiam na realização de exames em que os candidatos precisavam demonstrar não só alfabetização, mas também conhecimento de matemática, de poesia, de noções técnicas e humanistas (LEWIS, 2012). Nenhuma tradição estatal equivalente se encontra na América Latina onde o acesso aos escritórios estatais continuam a depender, em grande parte, das relações pessoais e dos graus de parentesco.

\section{Conclusão}

O desempenho econômico da Ásia Oriental e da América Latina distingue-se em dois períodos históricos. Do século $\mathrm{XIX}$ até meados do $\mathrm{XX}$, as economias latinoamericanas foram mais dinâmicas e apresentaram diferenças claras em relação à asiática em termos de PIB per capita; de salários; de níveis de condições de urbanização e de vida. Depois, algumas economias da Ásia como Coreia do Sul, Taiwan, Singapura e Hong Kong superaram as economias da América Latina. $E$, mais recentemente, o mesmo ocorre com a China e toda a sua área de influência, especialmente o Vietnã. Entendemos que as vantagens latino-americanas na primeira etapa se explicam pela dotação de recursos naturais que proporcionaram uma posição mais favorável de inserção na divisão internacional do trabalho diante das lideranças industriais, ou seja, as populações europeias e norteamericanas. A partir da década de 1950, esse cenário se inverteu. Enquanto a América Latina enfrentou o desmonte de seus mecanismos de proteção, os Estados asiáticos 


\section{NEIBA}

VOLUME VII

Dossiê: SimpoRI 2018

\section{8}

recuperaram sua autonomia política por conta de seus desafios geopolíticos. Esse contexto gerou profundas e persistentes mudanças no ritmo de industrialização destinado ao mercado mundial. As condições de guerra latente e a tradição burocrática permitiram aos Estados da
Ásia maiores níveis de coesão, apesar de incluírem as classes dos novos empresários no planejamento dos processos de acumulação e de poder político - algo inimaginável nas condições neoliberais predominantes hoje na América Latina. 


\section{NEIBA}

VOLUME VII

\section{Dossiê: SimpoRI 2018}

\section{8}

\section{BIBLIOGRAFIA}

ARRIGHI, J. Adam Smith in Beijing. Lineages of the twenty-first Century. Verso, 2009.

BAIROCH, P. International Industrialization Levels from 1750 to 1980. Journal of European Economic History; Rome Tomo 11, N. ${ }^{\circ}$, (Fall 1982): 269 .

DICKSON, B. The Party, Private Entrepreneurs, and Prospects for Political Change, 2003.

FINDLAY, R.; O'ROURKE, K. Power and Plenty. Trade, War, and the World Economy in the Second Millennium. Princeton University Press, 2009.

GONZALO, M. A Long-Term Narrative on India from Latin America: peripherization, national system of innovation and autonomous expenditures. Tese de Doutorado, IE-UFRJ, 2018.

HAMASHITA, T. China, East Asia and the Global Economy. Regional and historical perspectives. Routledge, 2008.

JONES, E. The European Miracle: Environments, Economies and Geopolitics in the History of Europe and Asia (3rd ed.), Cambridge University Press, 1981.

LEWIS, M. E. China's Cosmopolitan Empire: The Tang Dynasty. Harvard University Press, 2012.

LYRIO, M. C. A Ascensão da China como Potência. Fundamentos Políticos Internos. Editora Fundação Alexandra Gusmão, 2010.

LYNCH, J. Las Revoluciones Hispanoamericanas. Seix Barral, 1976.

MCNALLY, C.; WRIGHT, T. Sources of Social Supportfor China' current political order: the 'thick embeddedness'of the private capital holders. Communist and Post-Communist Studies, pp 189-198.

NAYYAR, D. Catch Up. Developing Countries in the World Economy. Oxford University Press, 2013.

NOGUEIRA, I. Estado e capital em uma China com classes. Revista de Economia Contemporância, Rio de Janeiro, 2018.

NOVAIS, F. Portugual e Brasil na Crise do Antigo Sistema Colonial (1777-1808). Editora Hucitec, São Paulo, 1989.

POMERANZ, K. The Great Divergence: China, Europe, and the Making of the Modern World Economy, Princeton University Press, 2000.

PORTELLA FILHO, P. O ajustamento na América Latina: crítica ao modelo de Washington. Lua Nova: Revista de Cultura e Política, $n$. 32, São Paulo, 1994.

SAYLOR, R. State Building in Boom Times. Commodities and Coalitions in Latin America and Africa. Oxford University Press, 2014. 